\title{
World Journal of Visualization of pleural fissures in infants on computed tomography
}

\author{
Andrew Phelps, ${ }^{1}$ Cynthia Tan, ${ }^{2}$ Saveen Ahuja, ${ }^{3}$ Dean Kolnick, ${ }^{4}$ Jesse Courtier, ${ }^{1}$ \\ John D MacKenzie ${ }^{1}$
}

To cite: Phelps A, Tan C, Ahuja S, et al. Visualization of pleural fissures in infants on computed tomography. World Jnl Ped Surgery 2019;2:e000034. doi:10.1136/wjps-2018-000034

Received 2 January 2019 Revised 15 January 2019 Accepted 16 January 2019

\section{ABSTRACT}

Purpose For infants with prenatally detected lung lesions, a chest CT is performed prior to surgery. The chest CT is performed as close to the surgery date as possible, because it is presumed that the visualization of lung fissures would be poor in the immediate neonatal setting. However, this presumption has never been formally studied. The purpose of this study is to assess differences in lung fissure visualization on chest CT in different infant age groups.

Methods This was a retrospective study of clinically indicated chest CT approved by the institutional review board performed in infants of different ages. The visibility of pleural fissures was subjectively assessed by three pediatric radiologists who were blinded to age group.

Results In the 0-2 months age group, $80 \%$ of all fissure segments were visible versus $92 \%$ in the $5-6$ months group $(p=0.04)$ and $95 \%$ in the $7-9$ months group $(p=0.01)$.

Conclusions The ability to visualize pleural fissures on CT increases with infant age. This observation should be taken into consideration when choosing the optimal timing of preoperative CT for asymptomatic congenital lung lesions.

\section{INTRODUCTION}

The most common congenital lung lesion in infants is a congenital pulmonary airway malformation, with a reported incidence between $1 / 2400$ and $1 / 35000 .^{1-5}$ At the authors' institution, preoperative CT for a congenital lung lesion is performed prior to surgical resection. CT is useful for preoperative planning to establish the size and location of the lung lesion, and visualization of the lung fissures helps establish the involved lobe. At the authors' institution, CT is delayed until closer to the surgery date, with the presumption that the visualization of lung fissures would be poor in the immediate neonatal setting, due to smaller patient size. However, this presumption has never been formally studied in infants, as all previous radiology research on pleural fissure anatomy on CT has all been in adults. ${ }^{6-10}$ The hypothesis of this study is that the CT visibility of pleural fissures increases in older infants. The results of this study will hopefully assist pediatric surgeons and radiologists in determining the optimal timing of preoperative CT imaging of congenital lung lesions.

\section{METHODS}

Study design

This study was a retrospective chart review.

\section{Study population}

All patients included in the study were infants who underwent a clinically indicated contrast-enhanced chest CT at a single academic pediatric hospital during an 8-year time period (September 2007 to March 2014). The indications for the CT included, but were not limited to, prenatally detected lung lesions. Three age groups were selected: 0-2 months, 5-6 months, and 7-9 months. There were several reasons for selecting these specific age ranges. First, the $0-2$ months group was selected to answer the question: Should preoperative CT of known congenital lung lesions be performed in the inpatient neonatal period, before the patient has been discharged from the neonatal unit? Second, age groups of the 5-6 months and 7-9 months were selected to answer the question: Is it sufficient to perform a preoperative CT a few months before surgery or should the CT be performed closer to the actual surgery date (ie, assuming the surgery is performed at approximately 9 months)? Each CT study represented a unique patient, with no repeat patients or repeat CT examinations used within or between age groups.

\section{Imaging parameters}

All studies were performed on a 64-slice multidetector scanner (Discovery CT 750 HD, GE Healthcare, Milwaukee, WI) with the following weight-based settings: (A) 80 $\mathrm{kVp}$ and max $240 \mathrm{~mA}$ for infants $<7.5 \mathrm{~kg}$ and (b) $100 \mathrm{kVp}$ and max $135 \mathrm{~mA}$ for infants $>7.5 \mathrm{~kg}$. The remaining CT parameters were the same for all patients: noise index 14, rotation time $0.5 \mathrm{~s}$, slice thickness $2.5 \mathrm{~mm}$, pitch 1.375. Each CT was performed under 


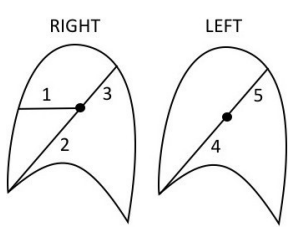

Figure 1 Sagittal sections of the right and left lungs.

There were five fissure segments evaluated in each patient, including: (1) right minor fissure, (2) right major fissure anterior segment, (3) right major fissure posterior segment, (4) left major fissure anterior segment, and (5) left major fissure posterior segment.

anesthesia with positive pressure breath hold with patient positioned supine with both arms elevated. All CT scans were performed with intravenous contrast. Iohexol 350 $\mathrm{mg} / \mathrm{mL}$ intravenous contrast was injected at $2 \mathrm{~mL} / \mathrm{s}$ at a volume of $2 \mathrm{~mL} / \mathrm{kg}$ with acquisition obtained $5 \mathrm{~s}$ after completion of contrast injection. Lung images were created at $1.25 \mathrm{~mm}$ thickness using either adaptive statistical iterative reconstruction $(30 \%$ blend with filtered back projection) or model-based iterative reconstruction.

\section{Assessment of lung fissures}

All assessments were performed on diagnostic quality workstation (Barco, Fremont, CA; Agfa, Greenville, SC) in low-level lighting clinical radiology reading room. Three board-certified pediatric radiologists (postfellowship years of experience: $2,5,7$ ) reviewed each case and recorded whether or not a fissure or fissure segment was visible. Fissure segment visibility was scored in a binary fashion: (A) visible or (B) not visible. The radiologists were blinded to patient age. There were five fissure segments evaluated in each patient: (1) right minor fissure, (2) right major fissure anterior segment, (3) right major fissure posterior segment, (4) left major fissure anterior segment, and (5) left major fissure posterior segment (figure 1). The radiologist was allowed to use any available reformat (axial, sagittal, or coronal reformat) to make the assessment of fissure visibility.

\section{Statistical analysis}

A fissure segment was counted as visible only if all three radiologists were in agreement. A $\chi^{2}$ test was performed to compare different proportions of fissure segment visibility between the different age groups. An online calculator was used to generate $p$ values. ${ }^{11}$
RESULTS

\section{Demographics}

All patients were seen at a single academic pediatric hospital. During the study period, 124 consecutive CT examinations were identified in the queried age groups. After excluding repeat examinations, repeat patients, technically inadequate CT studies, and non-chest anatomy, a total of 40 unique patients remained: 9 in the 0-2 months group, 16 in the 5-6 months group, and 15 in the 7-9 months group. The patient demographics are summarized in table 1.

\section{Fissure visibility}

A total of 200 fissure segments were evaluated in the 40 unique patients (five fissure segments per patient, with 45 fissure segments in the 0-2 months group, 80 fissure segments in the 5-6 months group, and 75 fissure segments in the 7-9 months group). Of the 200 fissure segments evaluated, 181 (91\%) were visible to all three radiologists and $1(0.5 \%)$ was not visible to all three radiologists. In the remaining 18 (9\%) fissure segments, the three radiologists disagreed about the visibility.

The lung fissure segments were more frequently visible (to all three radiologists) in the older infants compared with younger infants (table 2 ). In the $0-2$ months group, $80 \%$ of all fissure segments were visible to all three radiologists, compared with $92 \%$ of fissure segments in the 5-6 months group ( $\mathrm{p}=0.04)$ and $95 \%$ in the $7-9$ months group $(\mathrm{p}=0.01)$. When combining all age groups, the right major fissure anterior segment was the most visible segment (seen in $95 \%$ of all patients) whereas the right minor fissure was the least visible segment (seen in $80 \%$ of all patients); this difference in rate of visibility was statistically significant $(\mathrm{p}=0.04)$. The remaining fissure segments were visible in $93 \%$ of all patients; however, this rate was not significantly different from the rate of visibility of the right minor fissure $(\mathrm{p}=0.09)$. Figure 2 shows an example of an older infant in whom all three radiologists agreed that all of the fissure segments were visible. Figure 3 shows the one example of a younger infant in whom all three radiologists agreed that the right minor fissure was not visible.

\section{DISCUSSION}

The increased use of routine prenatal ultrasound has resulted in the increased detection of congenital lung

\begin{tabular}{|c|c|c|c|c|}
\hline $\begin{array}{l}\begin{array}{l}\text { Ages } \\
\text { (months) }\end{array} \\
\end{array}$ & $\mathbf{n}$ & $\begin{array}{l}\text { Mean age } \\
\text { (months) }\end{array}$ & $\begin{array}{l}\text { Female:male } \\
\text { patients }(n)\end{array}$ & Indications for CT \\
\hline $0-2$ & 9 & 0.9 & $6: 3$ & $\begin{array}{l}\text { Prenatal chest mass }(n=4) \text {, chest radiograph abnormality }(n=2) \text {, extrathoracic } \\
\text { neoplasm }(n=1) \text {, gastrointestinal bleed }(n=1) \text {, pulmonary hypertension }(n=1)\end{array}$ \\
\hline $5-6$ & 16 & 5.4 & $6: 10$ & $\begin{array}{l}\text { Prenatal chest mass }(n=7) \text {, chest radiograph abnormality }(n=4) \text {, extrathoracic } \\
\text { neoplasm }(n=4) \text {, congenital heart disease }(n=1)\end{array}$ \\
\hline $7-9$ & 15 & 7.6 & $5: 10$ & $\begin{array}{l}\text { Prenatal chest mass }(n=7) \text {, congenital heart disease }(n=3) \text {, chest radiograph } \\
\text { abnormality }(n=2) \text {, infection }(n=2) \text {, extrathoracic neoplasm }(n=1)\end{array}$ \\
\hline
\end{tabular}


Table 2 Fissure visibility in different age groups (all three radiologists in agreement)

\begin{tabular}{lcclccc}
\hline $\begin{array}{l}\text { Age } \\
\text { group }\end{array}$ & $\begin{array}{l}\text { Right minor } \\
\text { fissure (\%) }\end{array}$ & $\begin{array}{l}\text { Right major } \\
\text { fissure } \\
\text { (anterior) (\%) }\end{array}$ & $\begin{array}{l}\text { Right major } \\
\text { fissure } \\
\text { (posterior) (\%) }\end{array}$ & $\begin{array}{l}\text { Left major } \\
\text { fissure } \\
\text { (anterior) (\%) }\end{array}$ & $\begin{array}{l}\text { Left major } \\
\text { fissure } \\
\text { (posterior) (\%) }\end{array}$ & $\begin{array}{l}\text { All fissure } \\
\text { segments (\%) }\end{array}$ \\
\hline 0-2 months & $6 / 9(67)$ & $7 / 9(78)$ & $7 / 9(78)$ & $8 / 9(89)$ & $8 / 9(89)$ & $36 / 45(80)$ \\
5-6 months & $13 / 16(94)$ & $16 / 16(100)$ & $15 / 16(94)$ & $15 / 16(94)$ & $15 / 16(94)$ & $74 / 80(92)$ \\
\hline 7-9 months & $13 / 15(87)$ & $15 / 15(100)$ & $15 / 15(100)$ & $14 / 15(93)$ & $14 / 15(93)$ & $71 / 75(95)$ \\
\hline All age groups & $32 / 40(80)$ & $38 / 40(95)$ & $37 / 40(93)$ & $37 / 40(93)$ & $37 / 40(93)$ & $181 / 200(91)$ \\
\hline
\end{tabular}

lesions. ${ }^{1-4} 12$ Most surgeons choose to resect radiologically identifiable lung lesions in infants due to the longterm risks of infection and malignancy. ${ }^{45-16}$ Lobectomy is the most common surgical operation for congenital lung lesions. ${ }^{17} 18$ Surgery is typically performed acutely in symptomatic patients (usually pneumonia or respiratory distress) and before 10-12 months in asymptomatic patients. ${ }^{15} 12131719$ The justifications for performing surgery in asymptomatic patients before 12 months of age are threefold: (A) avoid infection, (B) allow for compensatory growth of the healthy lung, and $(\mathrm{C})$ detect unsuspected malignancy (eg, pleuropulmonary blastoma). ${ }^{512-14} 18-22$

Preoperative CT is performed for congenital lung lesions to confirm diagnosis and delineate the relationship between the lung lesion and the normal anatomical structures. ${ }^{16}$ The hypothesis of this study was that the CT visibility of lung fissures increases with infant age, and the results of this study supported the hypothesis. In the 0-2 months group, $80 \%$ of fissures were visualized compared with $92 \%$ and $95 \%$ of fissures in the age groups of 5-6 months and 7-9 months, respectively. Nearly all fissures were visible by 5 months of age, with no significant difference between the 5-6 months group and 7-9 months group. The implication of the results is that preoperative CT does not need to be performed in the neonatal setting and can be delayed until later in infancy, at a time that is convenient for the planned surgery.

The authors of this study propose three possible explanations for why the fissures were more difficult to visualize in the 0-2 months group. First, infants are considerably

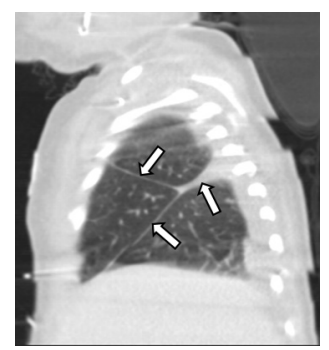

Figure 2 An older female infant (7-9 months group) with a neck abscess underwent a contrast-enhanced chest CT. In this sagittal reformat of the right lung, all three radiologists agreed that the pleural fissures were clearly visible (indicated by arrows). Of note, a pleural effusion was present, which likely enhanced visualization of the fissures, particularly the posterior segment of the right major fissure. smaller at $0-2$ months of age, so the smaller structures at 0-2 months will be less readily visualized or below limits of detectability by CT. A second possible explanation is that fissures are more difficult to see in smaller patients due to their higher respiratory rate. For this study, the CT scanner was a 64-slice detector, and newer generation scanners and techniques might allow for better anatomic detail in smaller patients. ${ }^{23} \mathrm{~A}$ third possible explanation for the results is that, in the absence of a healthy control group, the comparison was confounded by a higher rate of acute pathology in the younger infants. Sicker patients would have more lung opacities and volume loss that could obscure a pleural fissure, as was demonstrated in the patient in figure 3 .

There are multiple limitations in this study. This is a single-center study with a small sample size; therefore, the results may not be generalizable to all infant populations. Also, there was no asymptomatic control group and the study groups were not controlled for gender, patient weight, respiratory rate, or clinical indication; therefore, the different rates of fissure visibility may have not have been due to differences in patient age. The imaging findings were not correlated with clinical outcomes; therefore, no clinical conclusions can be drawn. The 0-2 months group had fewer patients than the other groups and was underpowered based on retrospective power analysis. Despite being underpowered, a statistically significant difference in fissure visibility was still detected between the 0-2 months group and the older age groups; this suggests that an adequately powered sample size

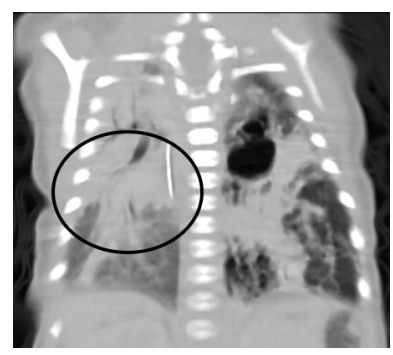

Figure 3 A younger female infant (0-2 months group) with a prenatally diagnosed lung lesion underwent a contrastenhanced chest CT. In this coronal reformat, all three radiologists agreed that the right minor fissure was not visible (the expected region of the right minor fissure is indicated with a circle). The lack of visibility was, at least in part, due to the mass effect of the left lung lesion resulting in right lung atelectasis. 
would have produced the same result. The ages of the patients were not continuous, which might have allowed for a stronger correlation to be drawn between age and fissure visibility. If more patients in different age groups had been evaluated, then a more accurate timeline of fissure visibility could have been elucidated. Lastly, this study did not evaluate for accessory fissures or fissure variants, which have been well described in adults undergoing CT. ${ }^{9}$

Within these limitations, however, we believe the results of this study support the practice of delaying the timing of preoperative CT for asymptomatic congenital lung lesions until closer to the elective surgery date. This delayed imaging approach has the added benefit of avoiding ionizing radiation in the neonatal period, at which time the long-term risks of ionizing radiation are higher. ${ }^{24}$ Future studies with larger patient populations using the latest CT equipment and techniques are needed to further validate the observations in this study.

In conclusion, the ability to visualize pleural fissures on CT increases with infant age. This observation should be taken into consideration when choosing the optimal timing of preoperative CT for asymptomatic congenital lung lesions.

Contributors All authors (AP, CT, SA, DK, JC, JDM) contributed to the design, data collection, data analysis, and manuscript write-up. AP was responsible for the overall content as guarantor.

Funding The authors have not declared a specific grant for this research from any funding agency in the public, commercial or not-for-profit sectors.

Competing interests None declared.

Patient consent Not required.

Ethics approval This study was approved by our institution's committee for human research, and the need for informed consent was waived.

Provenance and peer review Not commissioned; externally peer reviewed.

Open access This is an open access article distributed in accordance with the Creative Commons Attribution Non Commercial (CC BY-NC 4.0) license, which permits others to distribute, remix, adapt, build upon this work non-commercially, and license their derivative works on different terms, provided the original work is properly cited, appropriate credit is given, any changes made indicated, and the use is non-commercial. See: http://creativecommons.org/licenses/by-nc/4.0

\section{REFERENCES}

1. Sfakianaki AK, Copel JA. Congenital cystic lesions of the lung: congenital cystic adenomatoid malformation and bronchopulmonary sequestration. Rev Obstet Gynecol 2012;5:85-93.

2. Stocker LJ, Wellesley DG, Stanton MP, et al. The increasing incidence of foetal echogenic congenital lung malformations: an observational study. Prenat Diagn 2015;35:148-53.
3. Chikkannaiah P, Kangle R, Hawal M. Congenital cystic adenomatoid malformation of lung: report of two cases with review of literature. Lung India 2013;30:215-8.

4. Adzick NS, Harrison MR, Crombleholme TM, et al. Fetal lung lesions: management and outcome. Am J Obstet Gynecol 1998;179:884-9.

5. Stanton M, Njere I, Ade-Ajayi N, et al. Systematic review and metaanalysis of the postnatal management of congenital cystic lung lesions. J Pediatr Surg 2009;44:1027-33.

6. Proto AV, Ball JB. Computed tomography of the major and minor fissures. AJR Am J Roentgenol 1983;140:439-48.

7. Sofranik RM, Gross BH, Spizarny DL. Radiology of the pleural fissures. Clin Imaging 1992;16:221-9.

8. Hayashi K, Aziz A, Ashizawa K, et al. Radiographic and CT appearances of the major fissures. Radiographics 2001;21:861-74.

9. Heřmanová Z, Ctvrtlík F, Heřman M. Incomplete and accessory fissures of the lung evaluated by high-resolution computed tomography. Eur J Radiol 2014;83:595-9.

10. Heřmanová Z, Ctvrtlík F, Heřman M. Surface anatomy of the pulmonary fissures determined by high-resolution computed tomography. Clin Anat 2012;25:835-43.

11. Schoonjans F, 2018. MedCalc's Comparison of proportions calculator. Available: https://www.medcalc.org/calc/comparison_of_ proportions.php [Accessed 16 Jun 2018]

12. Hall NJ, Stanton MP. Long-term outcomes of congenital lung malformations. Semin Pediatr Surg 2017;26:311-6.

13. Laje P, Liechty KW. Postnatal management and outcome of prenatally diagnosed lung lesions. Prenat Diagn 2008;28:612-8.

14. Tsai AY, Liechty KW, Hedrick HL, et al. Outcomes after postnatal resection of prenatally diagnosed asymptomatic cystic lung lesions. J Pediatr Surg 2008;43:513-7.

15. Farrugia MK, Raza SA, Gould S, et al. Congenital lung lesions: classification and concordance of radiological appearance and surgical pathology. Pediatr Surg Int 2008;24:987-91.

16. Saeed A, Kazmierski M, Khan A, et al. Congenital lung lesions: preoperative three-dimensional reconstructed CT scan as the definitive investigation and surgical management. Eur $J$ Pediatr Surg 2013;23:53-6.

17. Aspirot A, Puligandla PS, Bouchard S, et al. A contemporary evaluation of surgical outcome in neonates and infants undergoing lung resection. J Pediatr Surg 2008;43:508-12.

18. Jelin EB, O'Hare EM, Jancelewicz T, et al. Optimal timing for elective resection of asymptomatic congenital pulmonary airway malformations. J Pediatr Surg 2018;53:1001-5.

19. Parikh DH, Rasiah SV. Congenital lung lesions: postnatal management and outcome. Semin Pediatr Surg 2015;24:160-7.

20. Pogoriler J, Swarr D, Kreiger P, et al. Congenital cystic lung lesions: redefining the natural distribution of subtypes and assessing the risk of malignancy. Am J Surg Pathol 2019;43:47-55.

21. Kapralik J, Wayne C, Chan E, et al. Surgical versus conservative management of congenital pulmonary airway malformation in children: a systematic review and meta-analysis. J Pediatr Surg 2016;51:508-12.

22. Morini F, Zani A, Conforti A, et al. Current Management of Congenital Pulmonary Airway Malformations: A "European Pediatric Surgeons' Association" Survey. Eur J Pediatr Surg 2018;28:1-5.

23. Rompel O, Glöckler M, Janka R, et al. Third-generation dual-source $70-\mathrm{kVp}$ chest CT angiography with advanced iterative reconstruction in young children: image quality and radiation dose reduction. Pediatr Radiol 2016;46:462-72.

24. Brenner D, Elliston C, Hall E, et al. Estimated risks of radiationinduced fatal cancer from pediatric CT. AJR Am J Roentgenol 2001;176:289-96. 